\title{
Motivation for Carsharing Services: the Role of Sustainability Values
}

\author{
Olga Saginova*, Ekaterina Tsenina, Dmitry Zavyalov, and Yuri Saginov \\ Plekhanov Russian University of Economics, 117997 Moscow, Russia
}

\begin{abstract}
Sharing, collaborative consumption, and on-demand systems, provide various models of peer-to-peer exchanges of tangible and intangible assets. Sharing is believed to demonstrate the basic values of the sustainable development with focus on environmental, economic, and social issues. Carsharing services demonstrate high growth rate with personal safety requirements changing focus with COVID-19 pandemic. The behaviour of carsharing users is determined by several main motives: getting pleasure from and enjoying new technologies, realizing users' views on reasonable consumption, strengthening one's reputation among members of the community, and obtaining economic benefits. The article presents the results of carsharing motivation research. Online survey and deliberative research sessions revealed the importance of sustainable development values for the young active consumers.
\end{abstract}

\section{Introduction}

The changes that have taken place in the global economy over the past 20 years have transformed the consumer markets and consumer behaviour. Innovations in the information and communication technologies are initiating digital transformation of the economy and society, turning information into an important and valuable resource. New technologies are changing everyday life, providing a greater choice of digital products, more complete information, additional distribution channels, ease of transactions for consumers. Consumption process is changing too, it is becoming more diverse, individualized, situational. The attitude of consumers to the goals and process of consumption is changing, and the importance of social and environmental motives is growing.

Researchers often explained consumers' indifference to ethics and sustainable consumption by the existing economic and institutional constraints, which made it easier for the consumers to stick to a pragmatic approach of consumerism [1]. The emergence and development of the concept and models of sharing economy supported by modern information technologies are affecting and gradually changing the consumer motives priorities. The sharing economy is growing exponentially [2], and carsharing in many countries is among the most popular sharing services. Due to the increasing importance of the sharing economy and its mobility models, it is necessary to understand the motivations

\footnotetext{
*Corresponding author: saginova.ov@rea.ru
} 
of consumers using different sharing services and the relation of these motives to consumers' value sets.

\section{Materials and Methods}

Research literature presents the benefits of sharing relating them to the values of sustainable development, since initially sharing was aimed at offering access to the unused or underutilized assets and resources [3-4]. It is believed that sharing economy motivates more responsible and sustainable consumption. Digital platforms that enable peer-to-peer exchanges provide consumers not only with access to assets that they cannot purchase, but also with an opportunity to earn additional income [5]. This paper is analysing the main drivers of young active consumers in using carsharing services and the relation of these motives to their values. The results of online survey and two deliberative research sessions are compared to the existing body of empirical data in recent research publication.

In the research literature, there are several terms that define the concept of exchanging or jointly using some assets or resources: collaborative consumption and collaborative economy, sharing consumption and sharing economy, peer economy, gig economy, ondemand economy, second-hand economy, distributed economy, etc. [6]. Analysis by Dredge and Gyimóthy [7] identified 17 different terms that describe these related concepts. Sharing is only one of the possible models, focused on per-to-peer exchange providing access to the assets rather than transfer of ownership [8]. The objective of this paper is finding out the motives of young active consumers for carsharing services, so we did not include discussions of differences between sharing, second-hand and on-demand economy segments here.

Empirical data on the carsharing users' motivation was collected by an online survey of young active consumers [9]. 164 valid questionnaires were collected. The questionnaire included 2 main sections: the first section identified the attitude of respondents to carsharing and frequency of using these services, as well as the desire and intention to use them in the future. In the second section respondents were asked to fill in their agreement or disagreement with the statements about carsharing. The statements were grouped into four parts, one for each of the established motives types. The level of agreement with each statement was estimated using a 7-point Likert scale from "completely agree" to "completely disagree". The integral assessment of each motivation was the sum of points for all responses for each type of motivation. The more points the respondent scored in the survey, the more pronounced the motivation was.

To understand whether sustainable development values are really part of young consumers value sets, two deliberative research sessions followed the online survey. Deliberative methods are used in various studies on socially important issues in the form of deliberative seminars, focus groups, surveys, and consultations [10]. The main rationale for deliberative research was to identify informed, balanced opinions of representatives of the target group on the issues of sustainable development that they may not have previously paid much attention to.

The deliberative discussion sessions were held on the MS Teams platform in June and October 2020. The October session was attended by 25 students of the Russian university master program, and the June session was attended by 20 students from France, Finland, Austria, Slovakia, and India who were participating in the international exchange programs of the same university. To prepare for the discussion, participants were provided with information materials on the sharing economy and carsharing model. Before the discussion participants were explained the procedure and rules of discussion and invited to share their opinions on the use of sharing services as an example of responsible consumption, leading to a more sustainable economic development. 


\section{Results and Discussion}

In the research literature, one can find empirical evidence of certain sharing economy drivers in the models of carsharing [11], housing rental [12], and exchange of tangible assets [13]. Many authors believe the key driver of sharing is maximizing personal utility [3,1]. Personal utility includes cost, consumer value, and convenience indicators. All of them relate to economic benefits of the sharing economy. Among the motives for sharing, enjoyment of the process and a sense of novelty have been also identified. Innovators among consumers get pleasure from the use of new technologies and digital platforms. This motivation can also be associated with maintaining one's reputation as an innovator and sophisticated user among the members of one's community. This last motive can be attributed to the social benefits of sharing [Ошибка! Источник ссылки не найден.]. Social benefits can also include a sense of belonging to a community or network [14].

Basing on the data available in the research articles, three groups of motives were identified: economic, ecological, and social. Economic motivation includes such factors as lower costs of access than those of ownership, saving money and time, ease of use. Social motivation includes user's reputation, recognition, and respect by the community. Ecological motives mean compliance with the principles of sustainable development, support for reasonable consumption, saving world's resources. We added a hedonistic motivation showing the feeling of enjoyment, and a sense of novelty.

Fuzzy sets were used to model the motivations for carsharing. To build models, the total range of scores (4 questions times 7 points maximum) was divided into parts, then the number of responses in each part of the questionnaire was calculated, as well as the proportion of responses and their accumulated scores. The accumulated share of responses sets the membership function of a fuzzy set that expresses the concept of the "type of motivation for carsharing" in terms of a point-based assessment of the motivation significance. These pairs of numbers can be joined by a curve using Microsoft Office Excel. Figure 1 shows models of motivation for sharing in the form of fuzzy sets. In our case, the fuzzy set is characterized by a sigmoid membership function.

We can conclude that the strongest motivation of respondents is economic - the desire to save money or time making the transaction easy and convenient. The second most important motivation is ecological - saving resources and using sustainable consumption. The significance of these motivations is greater than the average level for all motivations. It is interesting to note that at the value of slightly more than 20 , the curves of these motivations intersect, which indicates that there is a certain percentage of respondents for whom the ecological motivation is a priority over economic benefits. The third most important motivation is enjoyment from the process of carsharing. And the fourth, different from the others, the least significant, is reputation - improving the image or gaining recognition among the members of one's community. 


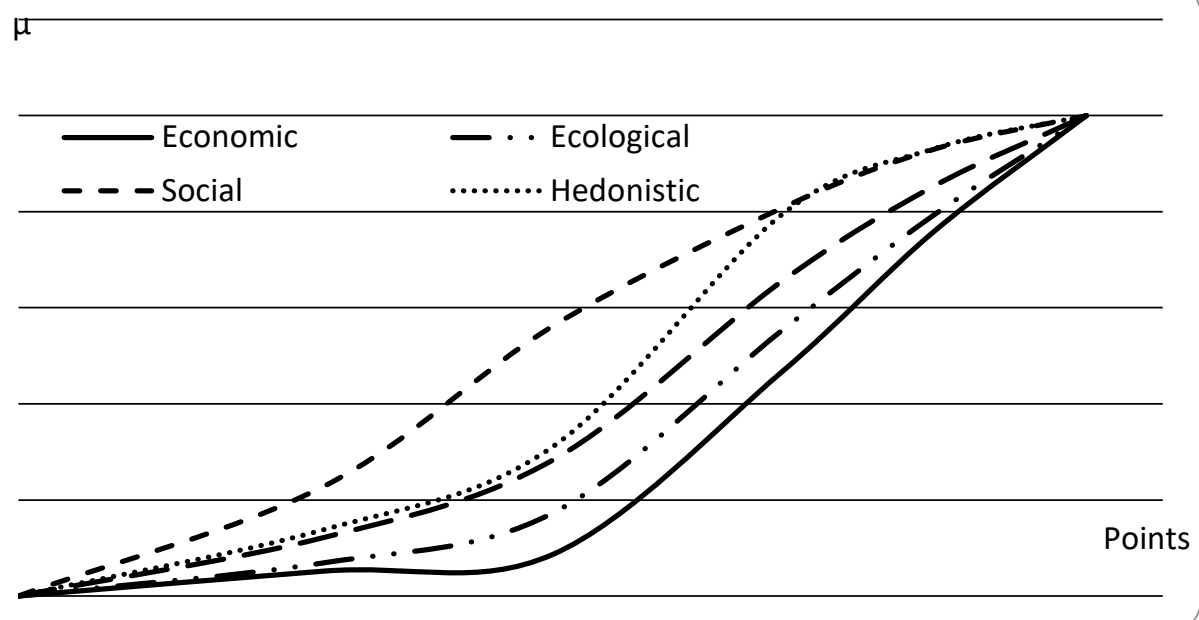

Fig. 1. Models of motivations for carsharing services

The participants of the deliberative research sessions confirmed the results of the online survey, showing that sustainable development, the desire to save natural resources and stick to sustainable consumption was an important factor in shaping their attitude to carsharing. The participants of the sessions gave examples of their own experience in carsharing and confirmed that they planned to use them more frequently in the future. All participants agreed that the ecological factor was an important motive for sharing. Even if the use of car sharing was driven by convenience ("you do not need to look for a parking space") or savings ("there is no money to buy a car, and taxis are too expensive"), ecological motives were still present and influenced the choice of consumers.

If we analyze the economic factor in more detail, the most influential motivation is financial savings, but along with this, people are driven by the desire to save time and effort (Fig.2).

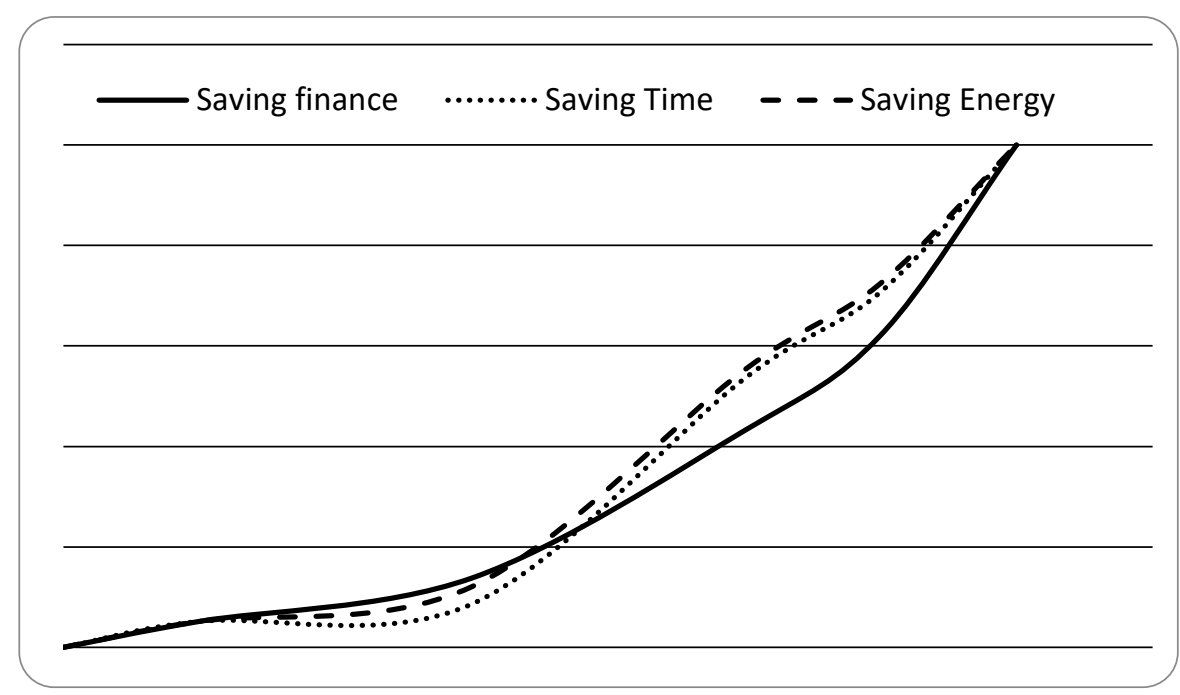

Fig. 2. Models of saving motivations for carsharing services 
The feeling of pleasure and novelty from using carsharing according to the participants of the discussion is relevant only at the beginning, during the first experience of carsharing. With more experience in sharing economy, the functions provided by the digital platforms are evaluated solely from the point of view of convenience.

The information provided to participants in the deliberative session was important: some participants mentioned that the information highlighted previously unknown aspects of sharing, helped to form, or even change the participants' opinions. This related, for example, to the priority of motives when using car sharing: participants concluded that ecological motives had a greater impact on the attitude of users than they had imagined, even if the direct driver to use the service was an economic benefit. This confirms the results of the existing published studies $[1,13]$.

Sharing is seen as a mode of consumption preferred by environmentally conscious consumers. Our results also suggest that considering carsharing as an activity leading to sustainable development can influence the spread of positive attitudes and more active use of the sharing services. The results of the study show that at the beginning of using sharing services, the consumer can enjoy the feeling of novelty, mastering new technologies, which plays a significant role in shaping the attitude and intention to use such services.

\section{Conclusions}

Comparing the results of this research to the data in other publications $[1,13,15]$ can show similar patterns of motives guiding consumers in using sharing services. Sustainable development being an important factor in the formation of positive attitudes towards sharing, the economic benefits are a strong motivator for intentions to participate in the sharing economy. Our results also support the idea that positioning sharing as a sustainable activity can result in increasing the frequency of its use.

This research can have several implications for the providers of digital carsharing platforms and services. The carsharing should be easy and comfortable to use because enjoyment is an important motivator at the beginning. Sharing services providers should not underestimate the importance of ecological motives and should consider using the ideas of sustainable consumption in their communications with potential users.

Future research can consider measuring the frequency of use affected by different motives, preference of different motives by consumers of different age groups, and the motivation pattern differences for those who are providing the assets and those who get access to the assets through sharing.

\section{Acknowledgements}

Prepared in the framework of the state task of the Ministry of Science and Higher Education No. FSSW2020-0009 "Developing a methodology for managing the competitiveness of enterprises in the field of commodity circulation in the digital economy".

\section{References}

1. J. Hamari, M. Sjöklint, A. Ukkonen, J. Assoc. Inf. Sci. Tech., 67(9), 2047 (2015)

2. PricewaterhouseCoopers, The Sharing Economy: Sizing the Revenue Opportunity (2015) http://www.pwc.co.uk/

3. R. Belk, Ann. Am. Acad. Polit. Ss., 611(1), 126 (2007)

4. M. Petrini, C. S. de Freitas, L. M. da Silveira, Revista de Administração Mackenzie, 18(5), 39 (2017) 
5. R. Botsman, Defining The Sharing Economy: What Is Collaborative Consumption And What Isn't? FastCompany, (2015) https://www.fastcompany.com/

6. Görög Georgina, Management, 13(2), 175 (2018)

7. D. Dredge, S. Gyimóthy, Tourism Recreation Research, 40(3), 286 (2015)

8. Y. Saginov, D. Zavyalov, O. Saginova, Russian Journal of Innovation Economics, 10(3), 1403 (2020)

9. R. Sidorchuk, A. Meshkov, B. Musatov, I. Skorobogatykh, D. Efimova, J. Appl. Econ., 13(1(55)), 150 (2018)

10. T. Burchardt, Qual. Res. J., 14(3) (2020)

11. F. Bardhi, G. W. Eckhardt, J. Consum. Res., 39(4), 881 (2012)

12. I. P. Tussyadiah, J. Pesonen, J. Travel Res., 55(8), 1

13. Möhlmann Mareike, J. Consum. Behav.,14(3), 193 (2015)

14. K. Frenken, T. Meelen, M. Arets, and P. van de Glind, The Guardian, May 20 (2015) https://www.theguardian.com/

15. Nijland, H., Van Meerkerk, J. and Hoen, A. PBL Netherland Environmental Assessment Agency, 1842 (2015) https://www.pbl.nl/ 